\title{
Selective reduction of pregnancy: a legal analysis
}

\author{
Alison Hall ${ }^{\star}$ Solicitor and doctoral student at Manchester University, Manchester
}

\begin{abstract}
This article examines the technique and legality of induced abortion of one or more fetuses in a multiple pregnancy, where the aim is the destruction of some but not all of the fetuses present (selective reduction of pregnancy). It concludes that since the legal status of the procedure in English law is unclear, it may be a criminal offence to perform selective reduction even where there is an ostensible clinical need. Moreover if the procedure is carried out negligently, and any infant damaged as a result is subsequently born alive, he or she may have a civil claim against the practitioner who carried out the procedure.
\end{abstract}

An unexpected product of the boom in assisted reproductive services has been the development by the medical profession of a procedure known as selective reduction of pregnancy, as a response to the iatrogenic multiple pregnancies generated by techniques of assisted reproduction. Selective reduction is carried out during the first trimester when a high order multiple pregnancy of three or more is typically reduced to twins. Crucially it is performed without knowledge of either the sex or the normality of the fetus "to improve the chances of healthy survival in the remaining conceptuses and to reduce the hazards to the mother", ${ }^{1}$ and is therefore distinct from the technique of selective feticide which is usually performed in the second trimester to kill a twin with a grave congenital abnormality, so to simultaneously prevent the birth of a seriously handicapped child and reduce the risks of pre-term birth in the remaining healthy fetus.

Although the technique of selective reduction has been adopted world-wide, doubt remains about its legality in England and Wales both because the relevant law is enshrined in four different statutes which are contradictory and ambiguous, and also because the wording of each of these statutes fails to

\section{Key Words}

Selective reduction; abortion; multiple pregnancy.

*Alison Hall is the winner of the UK Forum and Journal of Medical Ethics Essay Competition, 1995 address the practicalities of the technique: indeed despite the amendments made to the Abortion Act 1967 by the Human Fertilisation and Embryology N Act 1990 specifically with selective reduction in $v$ mind, a careful reading of all the statutes suggests that the technique may be illegal.

\section{Background}

In 1986, the overall multiple pregnancy rate for those undergoing in vitro fertilisation (IVF) was $24 \%$, a tenfold increase over the expected multiple pregnancy rate for the UK $(2 \%)$. The rise in triplet rates was even more startling - with 19 triple pregnancies representing a rate of $3.2 \%$ among those receiving IVF, equivalent to a hundredfold increase over the general population rate. ${ }^{2}$ This increase is directly attributable to two factors, namely the transfer into the uterus of more than one embryo with techniques such as IVF and gamete intrafallopian transfer (GIFT), and the administration of drugs to induce superovulation in anovulatory women.

Whilst the Human Fertilisation and Embryology Authority (HFEA) regulates the provision of IVF and GIFT using donated material, in accordance with the 1990 Act the use of superovulation remains largely unregulated. Both IVF and GIFT using donated material require a licence from the HFEA, whose code of practice prevents more than three embryos or pre-embryos from being transferred save in exceptional cases: ${ }^{2}$ persistent breach results in withdrawal of the licence required to offer these of techniques. Although the Royal College of $N$ Obstetricians and Gynaecologists published guide- N lines in 1994 urging that superovulation techniques be monitored by way of ultrasonography and bloodtesting, there are no sanctions for failing to comply with these guidelines, and centres which do not have $\stackrel{\oplus}{\rightarrow}$ the facilities and resources for monitoring are nevertheless continuing to offer superovulation treatment. ${ }^{3}$ Even if these guidelines were adhered to and accurate monitoring of pre-ovulatory follicles could be offered to all women undergoing superovulation, the incidence of multiple pregnancies in cycles induced with some hormone analogues such as 
human menopausal gonadotrophin (hMG) may still be as high as $10-20 \% .{ }^{4}$ Furthermore the guidelines do not affect the widespread and unregulated use of other ovulation-inducing drugs such as Clomid by general practitioners, which carry an estimated multiple pregnancy rate of $8 \% .^{3}$

Multiple pregnancies are problematic because they are strongly predictive of prematurity and low birth weight, which in turn are associated with increased levels of perinatal mortality and morbidity. Botting et al found that "compared with singletons, babies from triplet and higher order births are about six times more likely to be stillborn and live-born babies are ten times more likely to die during their first year". ${ }^{5}$ Another study of multiple births in England and Wales between 1975 and 1983 showed a perinatal mortality rate of 13.8 per 1,000 live and stillbirths for singleton pregnancies, rising to rates of 219 and 416 for quadruplet and sextuplet pregnancies respectively: of those born alive, the infant mortality rate rose from $11 \cdot 7 / 1000$ singleton live births to $220 / 1000$ in quads and $500 / 1000$ in sextuplets. ${ }^{6}$

The mothers of multiple pregnancies are also exposed to a number of serious risks, which may be life-threatening - for example hyperemesis (excessive vomiting) necessitating intravenous fluid therapy; hypertension (high blood pressure) leading to fits, cerebral haemorrhage or placental bleeding; and polyhydramnios (an excessive accumulation of fluid within the uterus) all of which may necessitate prolonged bed rest with its associated risks of thrombosis. ${ }^{1}$

\section{What does selective reduction of pregnancy involve?}

In selective reduction of multifetal pregnancies, three different approaches may be used: transcervical, transvaginal and transabdominal. Although the transcervical route, ${ }^{7}$ involving dilatation of the cervix and aspiration of the lowest sac using a canula, was first used up to the 9th week of gestation, spontaneous abortion and vaginal haemorrhage in women undergoing this technique ${ }^{8}$ led to the development of the transvaginal route. This involves the insertion of a needle into the sac closest to the vaginal wall, which is then aspirated (up to the 7 th week of gestation), or injected with potassium chloride or saline into the thorax, which kills the fetus. ${ }^{9}$ The transabdominal route, however, is now the most frequently used method: a needle is introduced through the mother's abdomen into the fetal thorax under ultrasound control, close to the fetal heart, and the fetus is killed either by mechanical trauma or injection of air, saline or potassium chloride. Selective reduction using this method is usually adopted between the 9th and 11 th gestational week. ${ }^{40-12}$

Whichever route is adopted, the procedure may be harmful in a number of different respects. First, it may carry a very high risk of complete abortion. Reported rates of abortion vary considerably - for example, Dommergues et $a l^{13}$ report a miscarriage rate of $23 \%$ after transabdominal procedures and $43 \%$ after transcervical procedures although other work using a combination of approaches has yielded a combined rate of about $20 \%{ }^{8}$ The perinatal mortality rate amongst triplet pregnancies not undergoing selective reduction is between $16 \%{ }^{6}$ and $20.5 \%{ }^{8}$ If the only basis on which the technique can be justified ethically is that it is likely to result in reduced perinatal, infant and maternal mortality and morbidity, then for very high multiple births (such as the octuplet pregnancy described by Evans et $a l^{14}$ ) selective reduction may be clinically justified, but on present evidence, the use of the procedure in triplet pregnancies is questionable, since although it slightly lengthens pregnancy, this is at the expense of increased perinatal mortality. ${ }^{15}$

Second, the procedure may necessitate unacceptable levels of fetal suffering, particularly where injection or mechanical intervention ("needling") has failed to result in the death of the fetus and the procedure has had to be repeated. Berkowitz ${ }^{8}$ notes that "the introduction of a needle into the thorax of a fetus in the first trimester, with or without the injection of a cardiotoxic substance, may result in severe bradycardia or even transient asystole with subsequent recovery of apparently normal cardiace activity ... .", necessitating repetition of the pro-? cedure at weekly intervals until the "objective has been achieved". This may have legal implications if the injured fetus is subsequently born alive. There could also be argument about the selection of the fetuses for "reduction" given that at 12 weeks gestational age, the karyotypic status and gender of the individual fetuses are rarely, if ever, known, and the only criterion by which selection takes place is that of their respective positions within their mother's uterus. If the selection of fetuses for termination is wholly dependent upon their relative positions in the uterus, then it will be ethically justifiable only to the extent that these positions are determined in a random fashion. As the process of assisted reproduction affects not only the number of embryos within the uterus, but also the destination of each fetus within the uterine wall, then selective reduction may not be fair - since the fetuses, if capable of being wronged, will be wronged first by the procedure that brought them into being and second by the method of its use.

\section{Is it legal?}

The law regulating selective reduction is contained in four separate statutes, the Offences Against the Person Act 1861 (OAPA), the Infant Life Preservation Act 1929 (ILPA), the Abortion Act 1967 and the Human Fertilisation and Embryology 
Act 1990, section 37(5) of which amended the provisions of the Abortion Act ostensibly to legalise the practice of selective reduction. With the exception of the 1990 act, when these laws were framed, it was impossible to imagine that one or more fetuses might be destroyed, allowing others to survive to term. Section 58 of the OAPA prohibits the doing of an act "with intent to procure the miscarriage of a woman with child". Doubts have been raised about the meaning of the word "miscarriage", and particularly whether it requires immediate or ultimate expulsion of the fetus from the uterus. If the morally and legally significant element of "miscarriage" is the proximate expulsion of the embryo from the uterus, rather than its destruction, selective reduction will not be capable of being regulated by the OAPA since selective reduction (if successful) does not result in the immediate expulsion of the embryo from the woman's body.

\section{Broad interpretation}

Even if the requirement is only for ultimate expulsion, this does not necessarily clarify the position, since it is unclear whether the products of conception are expelled from the uterus at all. ${ }^{16}$ The remains of the aborted fetus may be visible as an attachment to the placenta or may be absorbed completely and only visible upon pathological dissection of the placenta at delivery. If the definition of "miscarriage" was extended to include microscopic products of conception ultimately expelled from the uterus so that the OAPA covered selective reduction, this would criminalise cases in which spontaneous absorption has occurred with no human intervention, with inequitable consequences.

Legal academics John Keown ${ }^{17}$ and David Price ${ }^{18}$ both favour a broad interpretation of the OAPA so that any act designed to prevent continuing development of the fetus and live birth would be caught by it. Keown also concludes that, in the context of the intrauterine device and other methods of post-coital contraception, the use of the word "miscarriage" indicates "the legal irrelevance of implantation, and the intention of the legislature to prohibit abortion from the time of fertilisation". Other writers agree Glanville Williams notes that the words "miscarriage" and "abortion" are often used synonymously, and defines abortion as "feticide: the intentional destruction of the fetus in the womb or any untimely delivery brought about with the intent to cause the death of the fetus". ${ }^{19}$

If this interpretation is right, then selective reduction will be legal if it complies with the terms of the Abortion Act 1967 as amended by the 1990 act (the amended Abortion Act), and indeed advice in these terms was circulated to all practitioners performing IVF and GIFT using donated gametes. ${ }^{20}$ However, if the expulsion of the products of conception from the uterus constitute an essential element of miscarriage which does not always occur with selective reduction, then is selective reduction sometimes a criminal offence? Brazier ${ }^{21}$ suggests that it is inconsistent to construe the OAPA generally and the 1967 act literally and that for the purposes of criminal law, if the grounds of the 1967 act can be satisfied then the procedure is legal.

Assuming this to be the case, when does selective reduction comply with the amended Abortion Act? Again the wording of the statute causes problems of interpretation. Section 37(5) of the 1990 act confirms that an abortion of one of a number of fetuses is legal if it complies with the amended Abortion Act - but the amended Abortion Act only offers protection where, in the words of section 1(1), "a pregnancy is terminated". There has been considerable debate about whether the condition of pregnancy is specific to each individual fetus. If pregnancy means "the state of being with child" or "the state of the uterus in being pregnant" then the technique will fall outside the amended Abortion Act and can never be other than a criminal act. ${ }^{16}$

Even if the definition of "pregnancy" were to be resolved unambiguously by the courts, the amended grounds for abortion in sections 1(1)(a)-(d) of the amended Abortion Act also pose problems of interpretation. Whilst a lawful ground for abortion under section $1(1)(d)$ is the existence of a substantial risk that the child will be born seriously handicapped selective reduction, by definition, means that the health of the fetuses are unknown when the procedure occurs. Furthermore, the construction of this section of the act suggests that a general risk of future handicap to some children of a multiple pregnancy constitutes insufficient grounds for abortion. ${ }^{22}$

\section{Second criterion}

Selective reduction will only be legal under s.1(1)(a) where "the pregnancy has not exceeded its twentyfourth week and . . . the continuance of the pregnancy would involve risk, greater than if the pregnancy were terminated, of injury to the physical or mental health of the pregnant woman or any existing children of her family". Since current legal principles prohibit the fetus from qualifying "as an existing child endowed with legal personality and rights of its own"23 the health of the fetuses cannot be taken into account in this equation. As both sections $1(1)$ (a) and $1(1)$ (c) require the practitioner to balance the risks of "continuation of pregnancy" with those of "termination", this only leaves the ground under section $1(1)(b)$ as clearly available. This refers to termination "necessary to prevent grave permanent injury to the physical or mental health of the pregnant woman".

Morgan and Lee ${ }^{16}$ suggest that it is not enough to establish the general risk to the mother's physical and mental health of multiple pregnancy: a second 
and supplementary criterion must be satisfied - the intervention must be necessary to prevent injury. But they have surely missed the point. The wording of this section talks of prevention not reduction of risk. Selective reduction from three to two, or eight to three fetuses may still leave the mother in a position where she is exposed to all the potentially fatal complications of pregnancy referred to above. Furthermore the medical practitioners who seek to apply this section of the act cannot simply compare the risks of continuing with the pregnancy with the risks of termination, as they would be required to do with abortion of a singleton pregnancy: instead they must compare the comparative risks of continuing with, say, a quadruplet and triplet birth. Whilst a triplet pregnancy may carry reduced risks than a higher multiple-order birth, the woman is still left with the attendant risks to her health that the birth of triplets must pose, together with the risk of haemorrhage, infection and spontaneous abortion inherent in the process of selective reduction.

Other legal implications arise from the procedure itself. The fact that the techniques used to terminate the life of a fetus are not foolproof suggests that an iatrogenically handicapped child who was born alive might be able to bring a claim against the practitioner who caused his or her injuries. Firstly, civil liability in tort could arise from a negligently performed selective reduction procedure. Here the infant would have to prove on the balance of probabilities that his or her injuries arose from the negligent performance of the procedure and as a result of a tort against the mother, following the Congenital Disabilities (Civil Liability) Act 1976 (CDCLA). Where the mother has consented to the procedure, it will be almost impossible to establish that an assault took place against the mother, but a negligence claim brought against the practitioner who carried out the procedure might be successful. ${ }^{21}$ For example Dommergues et al ${ }^{13}$ noted a rare abdominal malformation (gastroschisis) in one fetus they had selected for termination, identified at 15 weeks by ultrasound, which they conclude was caused by "failed transabdominal needling at 11 weeks". Selective feticide of this "malformed" fetus was subsequently performed. If that child had survived he or she may have had an action in negligence if the court could be persuaded that the practitioner had failed to comply with a responsible body of medical opinion in carrying out the reduction. ${ }^{24}$

Secondly, the infant could bring an action in respect of the multiple pregnancy itself. It is arguable that with adequate monitoring by blood test and ultrasonography, very high multiple pregnancy rates should not occur and may even constitute a situation in which the doctrine of res ipsa loquitor (the circumstances speak for themselves) can be invoked. Certainly Evans et al $^{14}$ cite a case of septuplets in which only three survived - two with severe handicap, in which malpractice litigation had been instituted in the USA on account of the multiple pregnancy. In an equivalent English case, the provisions of the CDCLA would be satisfied if the child could prove that, in allowing the multiple pregnancy to occur, the practitioner was negligent and had failed to comply with responsible medical opinion. The mother may also be able to claim for her damages caused by the multiple pregnancy and the costs of raising the ensuing children.

\section{Conclusions}

The law and ethics of selective reduction of pregnancy have been dominated by a consequentialist perspective. In the medical literature, emphasis has been placed on the plight of the pregnant woman and the range of alternatives available to her. Not surprisingly, the prospect of complete abortion of all fetuses or alternatively allowing the pregnancy to proceed to term knowing that the probability of having any live healthy infants is extremely small, is particularly poignant given that a significant proportion of the women who have received infertility treatment have been trying to have children for many years and a multiple pregnancy may represent their final chance to achieve this dream. The clear responsibility for the prevention of multiplege pregnancies in women undergoing fertility treat ment lies with the medical profession. In the absence of an effective means of ensuring that multiple pregnancies will not be caused by the drugs used to treat infertility, ethical considerations such as respect for autonomy require that women must be thoroughly counselled prior to treatment about the probability of having a multiple birth. Furthermore, in the event of a multiple pregnancy arising, it is far from clear that selective reduction is a justifiable and legal treatment in all cases. Despite the reforms of the Abortion Act engendered by the 1990 act and inelegant attempts to justify the technique under the OAPA by semantic argument, the disparity between statute and current medical practice suggests that our continued reliance on the OAPA is anachronistic, and that a thorough overhaul of the legislation dealing with abortion is overdue. Quite apart from the confusion surrounding the definitions of "miscarriage", "pregnancy" and "termination" at the heart of the statutory framework in this country, the balancing of risk required by the amended Abortion Act suggests that in cases of twins, triplets and even quadruplets, the medical justification for proceeding with selective reduction may be absent. Furthermore, from an ethical standpoint, if such actions can only be justified on the basis that they enhance maternal autonomy, then unless society accepts that autonomy should trump other ethical principles such as beneficence and justice, selective reduction will be ethically unsound. 
Alison Hall is a solicitor and RGN and is currently studying for a PhD in Health Care Ethics at the Centre for Social Ethics and Policy, University of Manchester.

\section{References}

1 Howie PW. Selective reduction - medical aspects. In: Templeton AA, Cusine D, eds. Reproductive medicine and the law. Edinburgh: Churchill Livingstone, 1990: 25-32.

2 Voluntary Licensing Authority for Human 'In-Vitro' Fertilisation and Embryology. Third report. London: VLA, 1988.

3 British Broadcasting Support Services. Public eye: little miracles [factsheet]. Broadcast on BBC 21995 Jan 31.

4 Ron-el R. Complications of ovulation induction. In: Evers JLH, ed. Ovulation induction: the difficult patient. Balliere's Clinical Obstetrics and Gynaecology. International Practice and Research 1993; 7(2): 435-53.

5 Botting BJ, Macfarlane AJ, Price FV, eds. Three, four and more: $a$ study of triplet and higher order births. London: HMSO, 1990. cited in: Interim Licensing Authority for Human 'In-Vitro' Fertilisation and Embryology. Sixth report. London: VLA, 1991: 32-7.

6 Botting BJ, Davies IM, Macfarlane AJ. Recent Trends in the incidence of multiple births and associated mortality. Archives of Disease in Childhood 1987; 62: 941-50. Cited in reference 1.

7 Dumez Y, Oury JF. Method for first trimester selective abortion in multiple pregnancy. Contributions to Gynaecology and Obstetrics 1986; 15: 50-3.

8 Berkowitz RL, Lynch L, Chitkara U, Wilkins I, Mehalek KE, Alvarez E. Selective reduction of multifetal pregnancies in the first trimester. New England Fournal of Medicine 1988; 318: 1043-7.

9 Itskovitz J, Boldes R, Thaler I, Bronstein M, Erlik Y, Brandes JM. Transvaginal ultrasonography-guided aspiration of gestational sacs for selective abortion in multiple pregnancy. American fournal of Obstetrics and Gynecology 1989; 160: 215-7.

10 Porreco R, Burke MS, Hendrix ML. Multifetal reduc- tion of triplets and pregnancy outcome. Obstetrics and Gynecology 1991; 78: 335-9.

11 Lynch L, Berkowitz RL, Chitkara U, Alvarez E. Firsttrimester transabdominal multifetal pregnancy reduction: a report of 85 cases. Obstetrics and Gynecology 1990; 75: 735-8.

12 Tabsh KMA. Transabdominal multifetal pregnancy reduction: Report of 40 cases. Obstetrics and Gynecology 1990; 75: 739-41.

13 Dommergues $M$, Nisand I, Mandelbrot L, Isfer E, Randunovic N, Dumez Y. Embryo reduction in multifetal pregnancies after infertility therapy: obstetrical risks and perinatal benefits are related to operative strategy. Fertility and Sterility 1991; 55: 805-11.

14 Evans MI, Fletcher JC, Zador IR, Newton BW, Quigg MH, Struyk CD. Selective first-trimester termination in octuplet and quadruplet pregnancies: clinical and ethical issues. Obstetrics and Gynecology 1988; 71: 289-99.

15 Boulot P, Hedon B, Pelliccia G, et al. Obstetrical results after embryonic reductions performed on 34 multiple pregnancies. Human Reproduction 1990; 5: 1009-13.

16 Morgan D, Lee RG. Blackstone's guide to the Human Fertilisation and Embryology Act 1990. Abortion and embryo research - the new law. London: Blackstone Press Ltd, 1991.

17 Keown IJ. Miscarriage: a medico-legal analysis. Criminal Law Review 1984: 604.

18 Price DPT. Selective reduction and feticide: the 8 o parameters of abortion. Criminal Law Review 1988: 199-210.

19 Williams G. Textbook of criminal law [2nd ed]. 1983: 292.

20 Keown IJ. Why selective reduction could result in criminal proceedings. In: Voluntary Licensing Authority for Human 'In-Vitro' Fertilisation and Embryology. Third report. London: VLA, 1988: annex 4: 41 .

21 Brazier M. Unfinished feticide: a legal commentary. fournal of Medical Ethics 1990; 16: 68-70.

22 See reference 16: 59-60.

23 See reference 21: 69.

24 Bolam v Friern HMC (1957) 2 All ER 118. 